\title{
LEARNER LANGUAGE ANALYTIC METHODS AND PEDAGOGICAL IMPLICATIONS
}

\author{
Bronwen Dyson, University of Sydney \\ Dr Bronwen Dyson is Postgraduate Academic Writing Advisor in the Faculty of \\ Arts, University of Sydney. Her main research interests are the second language \\ acquisition of English, and its application to pedagogy, academic writing and \\ TESOL program evaluation. Her research is informed by a wide experience \\ teaching ESL, Second Language Acquisition, academic writing and Linguistics in \\ a range of educational contexts, including schools and universities. She has published \\ both nationally and internationally.
}

\begin{abstract}
Methods for analysing interlanguage have long aimed to capture learner language in its own right. By surveying the cognitive methods of Error Analysis, Obligatory Occasion Analysis and Frequency Analysis, this paper traces reformulations to attain this goal. The paper then focuses on Emergence Analysis, which fine-tunes learner language analysis by measuring the 'onset' of spoken grammar as hypothesised in Processability Theory (PT) (Pienemann, 1998, 2005a). Since doubts have been expressed regarding the emergence approach's rigour and pedagogical relevance, a study is presented which aims to provide a more in-depth and wide-ranging account of the 'onset' of. English grammar. Having sketched and amplified Processability Theory's predictions, the paper applies emergence analysis to the longitudinal development of two adolescent ESL learners. As well as exemplifying the rigour of the emergence procedures, the results show overall support for the more comprehensive predictions. The paper concludes that learner language analysis does not have a deficit emphasis on transition to the target language, as claimed by Firth and Wagner (1997, 2007). Indeed, such methods have a role in assessing developmental readiness in a learner-oriented approach to grammar teaching.
\end{abstract}

\section{INTRODUCTION}

Consistent with language pedagogy, research on 'interlanguage' has striven to understand the second language learner's perspective. Since their inception in the 1960s, learner language analytic methods have undergone a series of reformulations to avoid the 'comparative fallacy' of target language comparisons (Bley-Vroman, 1983). In fact, this shift has prompted the alternative term, 'learner language', 'the oral and written language produced by (second language) learners' (Ellis and Barkhuizen, 2005, p. 4). Thus, while vestiges of the 'comparative fallacy' endure in some cognitive SLA research, the major contemporary view of 'interlanguage' cannot be equated with transition to native 
speaker competence and linguistic failure. Yet, this is how Firth and Wagner (1997, 2007) characterise interlanguage, adding 'learning' and 'system' as two other undesirable concerns.

To explore the potential of learner language as a pedagogical tool, this paper evaluates existing cognitive methods in terms of their sensitivity to the trajectory of English as a Second Language (ESL) development. It traces how the cognitive methods have moved away from measures based on transition to the target language and towards ones which capture language development, learning and systematic use on learner terms. The paper then focuses on Emergence Analysis, which gauges the 'onset' of grammatical features, such as plurals, as hypothesised in Processability Theory (Pienemann, 1998, 2005a). However, Emergence Analysis has met with scepticism concerning its rigor (Ellis and Barkhuizen, 2005) and, due to its limited number of predictions, pedagogical relevance (Lightbown, 1998). In response, this paper presents an empirical study that aims to provide an in-depth and extended account of the 'onset' of English grammar in two adolescent ESL learners.

\section{ERROR ANALYSIS, OBLIGATORY OCCASION ANALYSIS AND FREOUENCY ANALYSIS}

This section sketches the cognitive methods known as Error Analysis (e.g. Corder, 1967), Obligatory Occasion Analysis (e.g. Dulay and Burt, 1973) and Frequency Analysis (e.g. Klein and Purdue, 1992). Space does not permit a full account of their analytical procedures, distinctive features and conclusions; however, this is available in Ellis and Barkhuizen (2005). To illustrate these methods, I take the innovative step of drawing on speech data from one of the two students (Amir) reported later in the empirical study (see 'The study' for bio-data information).

\section{ERROR ANALYSIS}

Developed during the 1960s and 1970s, Error Analysis (ErA) is a set of procedures for 'identifying, describing and explaining learner errors' (Ellis and Barkhuizen, 2005, p. 51ff). If we follow the EA procedures sketched in Figure 30.1, we would focus on the underlined words in the following excerpt from Amir's first sample. Here, we see that, in describing a picture, Amir made errors with verbs by omitting the -s suffix (3SG-s) on lexical verbs with third person singular subjects e.g. she want (Line 80). 


$\begin{array}{lll}\text { 79. } & \text { Interviewer. } & \text { yeah mhm. that's right. so what about this picture? } \\ \text { 80. } & \text { Amir: } & \text { eh. she want to buy. cheese? ... } \\ \text { 117. Interviewer: } & \text {... why else do you go to a friend's place Amir? } \\ \text { 118. Amir: } & \text { to. stay. eh to stay. in his house and talk } \\ \text { 119. Interviewer: } & \text { mhm. yeah. yeah. } \\ \text { 120. } & \text { Amir: } & \text { she talks to him }\end{array}$

An ErA would interpret such errors as attempts to learn English verbs and analyse their systematic features by counting the omissions (sixteen in the entire sample). Finding only one exception i.e. she talks (Line 120), it would determine that the errors were consistent and hence constituted a learner rule. In this way, an ErA sheds light on Amir's learning of English verb syntax. Nevertheless, by focusing on the errors and neglecting the single 3SG-s, this method emphasises transition to the target language and suggests linguistic failure.

Error Analysis: Collect a sample $\rightarrow$ identify grammatical errors $\rightarrow$ record error frequencies $\rightarrow$ explain errors $\rightarrow$ repeat procedure with other morphemes

Obligatory Occasion Analysis: Select a morpheme $\rightarrow$ identify and count obligatory occasions $\rightarrow$ count suppliance of morphemes $\rightarrow$ calculate accurate use as a percentage $\rightarrow$ order devices implicationally $\rightarrow$ repeat procedure with other morphemes.

Frequency Analysis: Select a linguistic variable $\rightarrow$ divide data into equal periods $\rightarrow$ identify different devices used $\rightarrow$ calculate frequencies $\rightarrow$ identify the dominant device at each point in time

Figure 30.1 Error Analysis, Obligatory Occasion Analysis and Frequency Analysis

Based on Ellis and Barkhuizen (2005)

\section{OBLIGATORY OCCASION ANALYSIS}

ErA's emphasis on transition was partly overcome by a method which originated in the 1970s, Obligatory Occasion Analysis (OOA). This method examines 'how accurately learners use specific linguistic (usually grammatical) features' (Ellis and Barkhuizen, 2005 , p. 73). If we continue our analysis of Amir's verb usage, now following the OOA procedures outlined in Figure 30.1, we can observe his learning trajectory. By counting the tokens of the target morpheme 3SG-s and its obligatory occasions, we would see that in the entire sample, Amir used this morpheme once in seventeen syntactic contexts. Expressed as a percentage of accurate use $(6 \%)$, this is not very systematic. If we then 
compare 3SG-s accuracy with a morpheme used in the excerpt below (the copula 'be'), we find that his accuracy with the copula $(100 \%)$ is higher than $3 \mathrm{SG}$-s.

$\begin{array}{lll}\text { 6. } & \text { Amir: } & \text {... eh. my brother is sixteen } \\ \text { 7. } & \text { Interviewer: } & \text { mhm } \\ \text { 8. } & \text { Amir: } & \text { and um I live in Peakhurst. in Victor Avenue }\end{array}$

By this comparison, OOA would predict a trajectory in which the copula is acquired before 3SG-s. In other words, OOA is able to describe ESL development rather than simply portray non-target usage. A transitional orientation remained, however, in OOA's usage of contexts to measure accuracy.

\section{FREQUENCY ANALYSIS}

Frequency analysis (FA) marked a further step towards assessing development rather than transition to the target language. This method 'examines the various devices a learner uses in order to perform a specific grammatical feature' (Ellis and Barkhuizen, 2005, p. 93) (see Figure 30.1). Since FA often uses longitudinal data, we could deepen our analysis by looking at how Amir's lexical verb morphology increased in frequency over the academic year.

In the vertical axis of Table 30.1, we see the learning 'devices' he employed, noting that the base lexical form of the verb is considered part of the trajectory, not as an error or a context as in ErA and OOA respectively. Looking across the six samples (the horizontal axis), we also observe a systematic pattern in which the base verb diminished and the 3SG-s increased. From the implicational ordering of these forms and the relations of dominance, an FA would conclude that Amir first acquired the base form (S1) and later 3SG-s (S4).

While a FA draws on known formulae detection measures, Ellis and Barkhuizen (2005, p. 101) point out that the separation of formulaic from productive use is problematic. How would we know, for example, whether Amir's single 3SG-s in Sample 1 (she talks to him) was formulaic or not?

\begin{tabular}{|l|c|c|c|c|c|c|}
\hline Samples & S1 & S2 & S3 & S4 & S5 & S6 \\
\hline 3 SG-s & $1(4 \%)$ & $1(6 \%)$ & $1(10 \%)$ & $7(78 \%)$ & $5(83 \%)$ & $16(89 \%)$ \\
\hline Base lexical verbs & $21(96 \%)$ & $17(94 \%)$ & $9(90 \%)$ & $2(22 \%)$ & $1(17 \%)$ & $2(11 \%)$ \\
\hline
\end{tabular}

Table 30.1 A frequency analysis of Amir's lexical verb morphology 


\section{EMERGENCE ANALYSIS}

By measuring the 'onset' or the first systematic use of a structure, Emergence Analysis (EA) locates the point in time 'when the learner has - in principle - grasped the learning task' (Pienemann, 1984, p. 191). As the measure of Processability Theory (Pienemann, 1998, 2005a) and its predecessors (e.g. Meisel, Clahsen and Pienemann, 1981), the criteria for establishing 'systematic use' have been refined to detect formulae.

There is on-going debate, however, regarding emergence as an acquisition criterion and pedagogical tool. Ellis and Barkhuizen, (2005) criticise emergence for its lack of rigor. To address this point, Pallotti (2007, p. 361) provides an 'explicit, operational definition' of the criterion and suggests that research should continue to explicitly elaborate the construct. Lightbown (1998; cf Hudson, 1993), in contrast, criticises the pedagogical relevance of stages research since it covers only a fraction of the English grammar taught in ESL classrooms: 14 in Pienemann, Johnston and Brindley (1988) and 15 in Pienemann (1998/2005b).

\section{PREDICTING EMERGENCE: PROCESSABILITY THEORY}

The emergence criterion is motivated by a processing view of second language development. According to PT (Pienemann, 1998, 2005a, 2005b), grammatical form appears in learners' speech when implicit, skill-based procedures become available. As words in the learner's lexicon are progressively analysed, the procedures encode greater and implicationally related 'exchanges of grammatical information' between constituents. The feature of Number, for instance, is 'exchanged' between the determiner and the noun in the phrase many dogs, a process formalised via the concept of feature unification in Lexical Functional Grammar (Bresnan, 2001; Falk, 2008). Consequently, the procedures form a hierarchy:

$$
\text { lemma } \subset \text { category } \subset \text { phrase (NP, VP) } \subset \text { sentence } \subset \text { subordinate clause (if applicable). }
$$

From this hierarchy, PT predicts developmental stages for morphology and syntax in which syntax emerges before morphology (Dyson, 2009a) and in which there will be 'gaps', since only certain structures of a stage may emerge around the same time (Pienemann, 1998).

As Table 30.2 outlines, PT advances the following hypotheses for ESL morphology. ${ }^{1}$ At the category stage, since no information can be exchanged, only 'lexical' morphemes (those attached to a single category e.g. PL-s) can emerge. At the phrasal stage, an inform- 
ation transfer occurs between Noun Phrase (NP) constituents, such as the determiner and the noun (permitting the Phrasal plural). Processing is also hypothesised within the Verb Phrase, namely a phrasal exchange between the auxiliary 'have' and the past participle, resulting in Tense agreement. At the sentence stage, interphrasal information is transferred across the main clause, such as between the subject and the verb (enabling 3rd singular $-\mathrm{s})$.

\begin{tabular}{|c|c|c|c|}
\hline Stage/Procedure & L2 outcome & Morphology & Examples \\
\hline 4 Sentence procedure & $\begin{array}{l}\text { Interphrasal } \\
\text { Morphology }\end{array}$ & 3SG-S & he eats at home \\
\hline 3 Phrasal procedures & $\begin{array}{l}\text { VP morphology } \\
\text { NP morphology }\end{array}$ & $\begin{array}{l}\text { Tense agreement } \\
\text { Phrasal } \\
\text { plural }\end{array}$ & $\begin{array}{l}\text { has seen } \\
\text { many dogs }\end{array}$ \\
\hline 2 Category procedure & $\begin{array}{l}\text { Lexical } \\
\text { morphology }\end{array}$ & $\begin{array}{l}\text { Plural-s } \\
\text { Possessive } \\
\text { pronoun }\end{array}$ & $\begin{array}{l}\text { the dogs } \\
\text { my dog }\end{array}$ \\
\hline 1 Lemma & $\begin{array}{l}\text { Invariant forms \& } \\
\text { formulae }\end{array}$ & & How are you? \\
\hline
\end{tabular}

Table 30.2 Processing procedures applied to English morphology

Based on Pienemann (2005b); Pienemann, Di Biase and Kawaguchi (2005)

Utilising the PT framework, the existing hypotheses for morphology can be augmented by the new hypotheses presented below:

- Inter-phrasal morphology at stage 4, involving an information exchange between the subject and verb:

- Agreement between subjects and non-lexical verbs e.g. 'be' and 'have' e.g. there are dogs (cf Parodi, 2000)

- Phrasal morphology at stage 3, with an exchange between two verbs in the clause:

- Aux+ing: auxiliary 'be' exchanges category information with a verbal complement encoding progressive aspect e.g. other one is standing in a. yellow dress (cf Falk, 2008) 
- Lexical morphology at stage 2, with a single verb in the clause and no information exchange:

- Past-ed e.g. he wanted to steal maybe the bicycle

- Past Irregular e.g. some animal was on the road

- V-ing e.g. I looking at it

As Table 30.3 summarises, PT makes the following predictions for ESL syntax. With no information exchange at the category stage, the syntax is canonical (SVO for English). Following this, at the phrasal stage, Adjuncts and wh- words are mapped to initial position. At the sentence procedure stage, topicalisation emerges due to the mapping of arguments to pre-subject position and 'inversion' occurs. At the final stage, the interclausal information exchange results in subordinate clause order.

\begin{tabular}{|l|l|l|l|}
\hline Stage/Procedure & L2 outcome & Syntax & Examples \\
\hline $\begin{array}{l}\text { 5 Subordinate clause } \\
\text { procedure }\end{array}$ & $\begin{array}{l}\text { Declarative order in } \\
\text { subordinate clauses }\end{array}$ & $\begin{array}{l}\text { Cancel } \\
\text { Inv }\end{array}$ & $\begin{array}{l}\text { I wonder why he sold } \\
\text { that car }\end{array}$ \\
\hline 4 Sentence procedure & $\begin{array}{l}\text { 'Inversion' in main } \\
\text { clauses }\end{array}$ & $\begin{array}{l}\text { Aux2nd } \\
\text { Do2nd }\end{array}$ & $\begin{array}{l}\text { What is she eating? } \\
\text { Why did he sell that car } \\
\text { Where is the cat? } \\
\text { Has he seen you }\end{array}$ \\
\hline 3 Phrasal procedures & $\begin{array}{l}\text { X(SVO) } \\
\text { X=any constituent } \\
\text { Yes/No Inv }\end{array}$ & $\begin{array}{l}\text { Topicalisation } \\
\text { Neg+V } \\
\text { Do Fronting } \\
\text { ADV Fronting } \\
\text { Wh- Fronting }\end{array}$ & $\begin{array}{l}\text { This I don't like } \\
\text { I cannot go } \\
\text { Do you like it } \\
\text { Now I go } \\
\text { Where you go? }\end{array}$ \\
\hline 2 Category procedure & Canonical order & SVO & She like the cat \\
\hline 1 Lemma & $\begin{array}{l}\text { Invariant forms \& } \\
\text { formulae }\end{array}$ & & How are you? \\
\hline
\end{tabular}

Table 30.3 Processing procedures applied to English syntax Based on Pienemann (2005b); Pienemann, Di Biase and Kawaguchi (2005) 
To these existing hypotheses for syntax, we can add the following new hypotheses, again based on the PT framework:

- Subordinate clauses at stage 5, involving an inter-clausal exchange

- That' Complementiser: a main and subordinate clause are linked by a syntactic exchange in which a lexical verb in the main clause takes a subordinate clause as its complement and marks it with the complementiser 'that' e.g. I think that she will marry that man

- Main clauses at stage 4, involving a sentence-level exchange

- Presentational/Existential 'there': the subject is remapped to post-verbal position following 'there' as a presentational element e.g. There are trees.

- Verb Phrase at stage 3, with an exchange between two verbs in the clause:

- 'To' Infinitive: two lexical verbs are linked via a syntactic exchange in which lexical verbs specify that they take non-finite complements marked by 'to' e.g. then she want to go home.

- Modal + Verb: a syntactic exchange occurs in which modal auxiliaries other than the tense-bearing modals 'will' and 'would' specify that their non-finite complements are bare infinitives e.g. I can speak German (cf Falk, 2008).

- Categories at Stage 2, with a single verb and no exchange in the clause:

- Base noun $(\mathrm{N})$

- Base verb (V)

- Base (or initial) form of the copula (Is): learners only use 'is' not forms which demonstrate features such as tense (e.g. 'was') or non-finiteness ('be').

\section{MEASURING EMERGENCE}

The first of the three steps in the EA procedure, a distributional analysis, is a quantitative presentation of the various structures in a sample. For each structure used, it records the frequency of tokens and contexts and determines whether the form is mapped onto a specific function. It differs from OOA in viewing contexts as the environments of rules, 
not as target occasions. Tables 30.4 to 30.7 are examples of (simplified) distributional analyses as well as the third step of implicational ordering (see Pienemann, 1998 for an explanation of distributional analysis [pp. 138-140] and an application of this approach to subject-verb agreement in the copula verb [pp. 123ff]).

The second step in the analysis separates systematic productivity from formulae. Productivity is measured by the number of tokens and systematic use by the lexical/morphological variety of those tokens. Since morphology is more susceptible to 'chunking', criteria for detecting productivity differ for morphology and syntax (Pienemann, 1998).

As Pallotti (2007) outlines, there are several current approaches to measuring systematic productivity within these domains. One approach, which was originally designed for syntax, requires one productive token in four contexts as evidence of emergence and no productive token in the same number of contexts as evidence of non-emergence (Pienemann, 1998). In contrast, considering contexts not relevant to the emergence of Japanese syntax, Kawaguchi (2005) required only one token. The second approach, which was developed for morphology, requires contrasts or minimal pairs. While Mansouri (2005) deemed necessary at least two lexical and two morphological contrasts, Zhang (2004) used a minimum of four tokens with lexical variation in at least two.

The third step in EA calculates language development via implicational ordering. In this procedure, each rule is theorised as a developmental stage; a rule which is 'learned later implies the presence of rules which are learned earlier' (Pienemann, 1998, p. 134).

\section{RESEARCH QUESTIONS}

As a method of capturing development on the learner's terms:

1. Does emergence analysis demonstrate rigor in examining learning, systematic use and language development?

2. Does emergence analysis support the more comprehensive and pedagogically-attuned set of PT ESL predictions (i.e. the existing and new hypotheses)?

\section{THE STUDY}

This study is based on my larger $\mathrm{PhD}$ investigation of variation in a group of adolescent learners attending an Intensive English Centre (Dyson, 2004). Since these students arrived in Australia with minimal English proficiency, they were initially placed in a beginners' class and attended the Centre for an academic year, the maximal period of time. This paper focuses on the sole pair who spoke Bosnian (L1) and German (L2): Amir (aged 
11) and Samia (aged 12). To collect oral data from the participants, audio-recordings, each lasting approximately one hour, were made while these two students carried out oral, communicative tasks on six different occasions (March, July, August, September, October and December 1999). The tasks were story guessing and interview (sample 1), picture guessing and description (sample 2), picture differences (sample 3), story guessing and asking questions about the interviewer's life (sample 4), story guessing (sample 5), and story guessing and ten questions (sample 6). The audio-recordings were transcribed and analysed according to EA.

Emergence was calculated in the following manner. Overall, although contexts are recorded, the study utilised a contrast-based not a context-based approach. For morphology, it followed Zhang (2004) in requiring a minimum of four tokens with lexical variation in at least two. To locate emergence in the non-lexical verb paradigms ('be', 'do' and 'have'), the sample had to include the initial (or base) form (respectively 'is', 'do' and 'have') and (at least) one full Noun Phrase. For syntax, due to the rather formulaic nature of some syntactic structures, the study required a more exacting version of Kawaguchi's (2005) criterion, namely at least two tokens which varied lexically or morphologically. In the case of Copula Inversion, this variation needed to include one full Noun Phrase. Following Pallotti (2007), the analysis of both domains took two other pieces of evidence into consideration: (1) over-generalisations of the rule in question e.g. I must did it as evidence of the Past form of 'do' and (2) continuity of use, defined as the production of a morpheme in four contexts following emergence in the previous sample. Echoes are not counted.

\section{RESULTS}

\section{AMIR'S DEVELOPMENT}

Tables 30.4 (morphology) and 30.5 (syntax) present the results of an EA of Amir's six samples. The distributional analysis of the first sample displays his diverse learning, including the 3SG-s and its contexts (Table 30.4) and the representation of these contexts as base lexical verbs (V) (Table 30.5).

The second step reveals whether Amir's learning became productive and systematic. For example, the morpheme 3SG-s has the status of 'not emerged' because there are insufficient tokens (1) and, hence, lexical variation (See Table 30.4). Contrastingly, the syntax of Copula Inversion is regarded as 'emerged' since Amir asked three such questions, e.g. was the woman in the car? (Line number 62) and is this the policeman? (64), which contained variability including one NP subject (the woman) (See Table 30.5). 


\begin{tabular}{|c|c|c|c|c|c|c|c|}
\hline Stages & Structures & S1 & S2 & S3 & S4 & S5 & S6 \\
\hline \multirow[t]{3}{*}{4} & 3SG-S & $1 / 17$ & $1 / 4$ & $1 / 1$ & $7 / 9$ & $5 / 6$ & $\begin{array}{c}13 / 15 \\
3>\end{array}$ \\
\hline & Has & / & $\begin{array}{l}1 / 1 \\
1>\end{array}$ & $1 / 1$ & $5 / 5$ & $2 / 2$ & $\begin{array}{l}4 / 4 \\
2>\end{array}$ \\
\hline & Are & / & $7 / 7$ & $3 / 3$ & $2 / 2$ & $32 / 32$ & $9 / 9$ \\
\hline \multirow[t]{3}{*}{3} & Tense agreement & l & / & l & $4 / 4$ & $1 / 1$ & l \\
\hline & Aux+ing & / & $12 / 14$ & $1 / 1$ & $11 / 11$ & $29 / 29$ & $26 / 26$ \\
\hline & $\begin{array}{l}\text { Phrasal } \\
\text { plural }\end{array}$ & $1 / 1$ & $2 / 2$ & $2 / 3$ & $6 / 6$ & $25 / 27$ & $6 / 6$ \\
\hline \multirow[t]{5}{*}{2} & Past -ed & $1 / 1$ & / & / & $12 / 12$ & $3 / 3$ & $\begin{array}{c}11 / 11 \\
1>\end{array}$ \\
\hline & Plural -s & / & $14 / 14$ & $4 / 4$ & $\begin{array}{c}11 / 12 \\
1>\end{array}$ & $22 / 23$ & $18 / 18$ \\
\hline & Past Ir & $7 / 7$ & $3 / 3$ & / & $\begin{array}{c}36 / 36 \\
1>\end{array}$ & $18 / 18$ & $\begin{array}{l}53 / \\
2>\end{array}$ \\
\hline & V-ing & / & $2 / 2$ & / & / & $1 / 1$ & $1 / 2$ \\
\hline & Possessive pronoun & $2 / 2$ & $4 / 4$ & $2 / 2$ & $3 / 3$ & $12 / 12$ & $15 / 15$ \\
\hline
\end{tabular}

Table 30.4 An emergence analysis of Amir's morphological development

Key: $\mathrm{S}$ = sample, Shaded numbers = emerged

By implicationally ordering the first sample's emerged forms, we can ascertain Amir's developmental stage and test the support for the established and new predictions. Since he demonstrated sufficient productivity in Copula Inversion (stage 4) but insufficient in the interphrasal morpheme, 3SG-s (stage 4), he can be located at sentence level processing for syntax but not for morphology. A quick look at his principally syntactic emergence shows onset at the preceding levels. For syntax, two of the structures in Table 30.5 are 
established predictions in PT: Stage 3 Adverb e.g. and then she want to go home (108) and Stage $2 \mathrm{SV}(\mathrm{O})$ e.g. she crash into the tree (98). Other structures conform to the additional hypotheses in this paper. We see the Verb Phrase syntax of the 'to' infinitive (toINF) e.g. she want to buy a new one (128) and Modal+V e.g. now I must learn the third language (44). In the SVO example the emergence of base nouns and verbs is also apparent. Finally, one type of lexical morphology, Past Irregular e.g. she was angry? (112), emerged (See Table 30.4).

In Sample 2's distributional analysis, we see a blossoming in Amir's learner language. Tables 30.4 and 30.5 show tokens (and contexts) of some existing and new predictions. For instance, morphologically, Amir expanded his repertoire with the lexical morphemes, Possessive Pronoun and PL-s e.g. the. uh knees (151), the phrasal Aux+ing e.g. I was just draw uh drawing the fire in the door (252) and the interphrasal are e.g. are there any windows on the castle? (254). Each of these morphemes displayed productivity, with Aux+ing showing more sophisticated variability than the predicted form: in addition to continuous aspect on the participle, there was past marking on the auxiliary.

While system was apparent in many Sample 2 forms, one interphrasal structure further illustrates how formulae are separated from productive syntax. In addition to two typically formulaic wh- questions, (what do you think?) Amir asked two lexically diverse questions, in which he placed the auxiliary after the wh- word, while not necessarily producing the correct form of the lexical verb. One of these question was the Do2nd type, in which hand uh does uh does he has? (313) while the other was Aux2nd, and what wh. is he going to do with it? (313) (see Table 30.5).

The implicational ordering of the emerged structures in this sample uncovers Amir's solid trajectory and his burgeoning at the interphrasal level. In addition to the ordered progression in his morphology and the emergence of Do2nd/Aux2nd, Amir progressed in other syntactic ways. He filled a stage 3 syntactic gap with $\mathrm{Neg}+\mathrm{V}$ e.g. well you don't know woman? (143), continued to use interphrasal Copula Inversion and added another stage 4 form, Y/N Inversion e.g. are they burning? (317). There is also support for two of the new interphrasal hypotheses. Amir framed the Presentational in declaratives e.g. there is a mother on the door (139) and interrogatives e.g. are there. some animals? (319). This interphrasal picture continues into sample 3, without new emergence.

Sample 4 reveals the consolidation of morphology with productivity and system apparent in the hierarchy of morphemes (Table 30.4). Two are interphrasal: the existing prediction, 3SG-s e.g. then another man comes on or kid comes. comes on a bike (42), and the newly hypothesised, Has (subject-verb agreement in the 'have' paradigm) e.g. the boy has not a teddy (42-44). Two are phrasal: Tense agreement e.g. maybe the ah. 
man with the yellows has stolen it (130) and the Phrasal plural e.g. these things (116) Another is lexical: Past -ed e.g. he wanted to steal (176).

\begin{tabular}{|c|c|c|c|c|c|c|c|}
\hline Stages & Structures & S1 & S2 & S3 & S4 & S5 & S6 \\
\hline \multirow[t]{2}{*}{5} & 'that' Complementizer & / & / & / & / & $1 / 1$ & $2 / 2$ \\
\hline & Cancel inversion & / & / & / & $0 / 1$ & $4 / 5$ & $0 / 1$ \\
\hline \multirow[t]{4}{*}{4} & $\begin{array}{l}\text { Aux2nd } \\
\text { Do2nd }\end{array}$ & l & $\begin{array}{c}2 / 2 \\
2 F\end{array}$ & $2 \mathrm{~F}$ & $\begin{array}{l}1 / 2 \\
1>\end{array}$ & $\begin{array}{c}5 / 5 \\
2 \mathrm{~F}\end{array}$ & $6 / 7$ \\
\hline & Presentational & l & $5 / 5$ & $13 / 13$ & $3 / 3$ & $17 / 17$ & $2 / 2$ \\
\hline & Y/N Inversion & / & $6 / 6$ & $7 / 7$ & $3 / 3$ & $2 / 2$ & $6 / 6$ \\
\hline & Copula Inversion & $\begin{array}{l}3 / 3 \\
3>\end{array}$ & $13 / 13$ & $2>$ & $1 / 1$ & $3 / 4$ & $19 / 19$ \\
\hline \multirow[t]{7}{*}{3} & $\mathrm{Neg}+\mathrm{V}$ & $1 / 1$ & $6 / 6$ & $1 / 1$ & $1 / 1$ & $16 / 16$ & $12 / 12$ \\
\hline & Do fronting & l & l & l & 1 & 1 & 1 \\
\hline & Topicalisation & l & l & l & l & l & I \\
\hline & ADV & $9 / 9$ & $1 / 1$ & $1 / 1$ & $17 / 17$ & $16 / 16$ & $6 / 6$ \\
\hline & Wh- Fronting & - & - & - & - & - & - \\
\hline & tolNF & $12 / 12$ & $7 / 7$ & $1 / 1$ & $2 / 2$ & $16 / 16$ & $21 / 21$ \\
\hline & Modal+V & $2 / 2$ & $4 / 4$ & 1 & $3 / 3$ & $24 / 24$ & $22 / 22$ \\
\hline \multirow[t]{4}{*}{2} & Is3SG & + & + & + & + & + & + \\
\hline & V & + & + & + & + & + & + \\
\hline & $N$ & + & + & + & + & + & + \\
\hline & SVO & $19 / 19$ & + & + & + & + & + \\
\hline
\end{tabular}

Table 30.5 An emergence analysis of Amir's syntactic development

Key: $+=$ emerged and very frequent, - = no instances of a structure which, as a learner form, has no contexts 
The final two samples elucidate systematic progress into stage 5. Amir negotiated subordinate clauses in sample 5 with Cancel Inversion e.g another. girl asks when she is going to have th. have it (81). Then, in sample 6 we see the emergence of the Complementiser 'that' e.g. and I think that she will marry that man (282).

In sum, this EA shows that Amir was processing at the interphrasal stage in sample 1 , consolidated this level in the three subsequent samples and then moved into interclausal processing in the final two samples. The findings exemplify how emergence analysis can reveal the step-wise development of processing capacity.

\section{SAMIA'S DEVELOPMENT}

The distributional summary of Samia's initial sample reveals some similarities and differences to the learning attempts noted in Amir's Sample 1. Samia resembled Amir in asking two Copula Inversion questions e.g. is this a policeman or a man? (152) (Table 30.7) but diverges by not producing a single non-formulaic token of 3SG-s (Table 30.6).

Delving deeper, we find system at the phrasal rather than the interphrasal stage in sample 1. The reliance on pronominal subjects in her Copula questions gives them a formulaic ring. However, as Table 30.7 displays, Samia was systematic in the existing PT predictions of Neg+V e.g. and she don't know what she doing. ah. yet (134) and Whfronting e.g. what she doing? (114) and the new hypothesis of Modal+V e.g. I can speak German (32).

Satisfying the implicational order, category morphology and syntax also emerged. Samia employed the Possessive pronoun e.g. my friends (16) and V-ing e.g. she. she um going to maybe holiday (96) (Table 30.6) and SV(O) with base verbs and nouns (Table 30.7).

The distributional analysis of Samia's sample 2 portrays a similar richness to Amir's, albeit with some different structures. Table 30.6, for instance, pinpoints morphological diversity, including with 3SG-s e.g. sits the girl on the carpet? (114) at the interphrasal level.

By further exploring formulae-detection measures, we see their importance in analysing the development of learners with a formulaic tendency, like Samia. Despite apparent system with 3SG-s in sample 2, the lack of any such tokens in four contexts in the subsequent sample showed that this morpheme did not emerge earlier. Samia seemed to 'piggy-back' in various ways, in this case apparently on L2 (German) inversion (see 114 above). While her Do/Aux2nd questions also appear quite formulaic, sufficient variability is evident e.g. how is the toilet look like? (66) and what's. what does the bath look like? (96). 


\begin{tabular}{|c|c|c|c|c|c|c|c|}
\hline Stages & Structures & S1 & S2 & S3 & S4 & S5 & S6 \\
\hline \multirow[t]{3}{*}{4} & 3SG-S & $\begin{array}{c}0 / 4 \\
1 \mathrm{~F}\end{array}$ & $\begin{array}{l}6 / 11 \\
2>\end{array}$ & $0 / 4$ & $11 / 21$ & $\begin{array}{c}16 / 16 \\
1>\end{array}$ & $36 / 37$ \\
\hline & Has3SG & / & $11 / 11$ & $4 / 4$ & $1 / 1$ & $2 / 2$ & $3 / 3$ \\
\hline & Are3PL & / & $6 / 6$ & $6 / 6$ & / & $11 / 11$ & $7 / 7$ \\
\hline \multirow[t]{3}{*}{3} & Tense agreement & $0 / 1$ & $0 / 1$ & / & $2 / 2$ & l & $1 / 1$ \\
\hline & Aux+ing & $0 / 3$ & $1 / 6$ & $6 / 6$ & $16 / 17$ & $11 / 11$ & $4 / 4$ \\
\hline & Phrasal plural & $1 / 1$ & $4 / 4$ & $2 / 2$ & $2 / 2$ & $4 / 4$ & $\begin{array}{l}0 / 1 \\
1>\end{array}$ \\
\hline \multirow[t]{5}{*}{2} & Past-ed & / & / & $1 / 1$ & $4 / 4$ & / & $5 / 5$ \\
\hline & Plural-s & $3 / 6$ & $\begin{array}{c}9 / 9 \\
1>\end{array}$ & $5 / 6$ & $\begin{array}{c}9 / 10 \\
3>\end{array}$ & $\begin{array}{c}7 / 7 \\
1>\end{array}$ & $\begin{array}{c}16 / 16 \\
1>\end{array}$ \\
\hline & Past Ir & $1 / 1$ & $\begin{array}{c}7 / 7 \\
1>\end{array}$ & $3 / 3$ & $\begin{array}{c}35 / 35 \\
1>\end{array}$ & $9 / 9$ & $\begin{array}{c}16 / 16 \\
1>\end{array}$ \\
\hline & V-ing & $4 / 4$ & $1 / 1$ & / & / & I & / \\
\hline & $\begin{array}{l}\text { Possessive } \\
\text { Pronoun }\end{array}$ & $2 / 3$ & $11 / 11$ & $7 / 7$ & $6 / 6$ & $8 / 8$ & $25 / 25$ \\
\hline
\end{tabular}

Table 30.6 An emergence analysis of Samia's morphological development

The landscape of Samia's sample 2 development surfaces from the implicational ordering. Table 30.6 shows the sequenced onset of the plurals: lexical PL- s e.g. there are dogs (263) and Phrasal plural e.g. any lines (94). The lexical morpheme, Past Irregular e.g. I told you before (275) also emerged. In syntax, Table 30.7 displays a sequence up to the interphrasal stage: we see the established syntax of Adverb Fronting, Y/N Inversion e.g. can you ask me questions? (250) and Copula Inversion e.g. where is the window? (56). The emergence of the newly hypothesised Presentational (see 263 above) and, in 
Table 30.6, subject-verb agreement via 'are' and 'has' add further evidence to placement at the interphrasal stage. We also see support for the hypothesised stage 3 syntactic structure, 'to' Infinitive e.g. he want to use the power (314) (see Table 30.7).

\begin{tabular}{|c|c|c|c|c|c|c|c|}
\hline Stages & Structures & S1 & S2 & S3 & S4 & S5 & S6 \\
\hline \multirow[t]{2}{*}{5} & 'that' COMP & / & $1 / 1$ & $1 / 1$ & $2 / 2$ & $1 / 1$ & $2 / 2$ \\
\hline & Cancel inversion & l & l & l & $3 / 6$ & / & / \\
\hline \multirow[t]{4}{*}{4} & $\begin{array}{l}\text { Aux2nd } \\
\text { Do2nd }\end{array}$ & $0 / 3$ & $9 / 9$ & $\begin{array}{l}0 / 1 \\
1 F\end{array}$ & $\begin{array}{c}3 / 6 \\
1>\end{array}$ & $\begin{array}{c}5 / 5 \\
1 F\end{array}$ & $\begin{array}{c}5 / 5 \\
1 F\end{array}$ \\
\hline & Presentational & l & 18/18 & $6 / 6$ & $2 / 2$ & l & $3 / 3$ \\
\hline & $\mathrm{Y} / \mathrm{N}$ Inversion & $1 / 1$ & $12 / 12$ & $10 / 10$ & $\begin{array}{l}4 / 4 \\
1>\end{array}$ & $7 / 7$ & $6 / 6$ \\
\hline & Copula Inversion & $2 \mathrm{~F}$ & $\begin{array}{c}12 / 14 \\
1 F\end{array}$ & $3 / 3$ & I & $8 / 8$ & $17 / 18$ \\
\hline \multirow[t]{7}{*}{3} & $\mathrm{Neg}+\mathrm{V}$ & $7 / 7$ & $7 / 7$ & $9 / 9$ & $3 / 3$ & $11 / 11$ & $6 / 6$ \\
\hline & Do Fronting & 1 & 1 & 1 & 1 & 1 & 1 \\
\hline & Topicalisation & / & / & I & 1 & 1 & / \\
\hline & Adverb Fronting & I & $2 / 2$ & $1 / 1$ & $24 / 24$ & $19 / 19$ & $17 / 17$ \\
\hline & Wh- Fronting & 5 & - & - & - & - & - \\
\hline & tolNF & $1 / 1$ & $2 / 2$ & / & l & $8 / 8$ & $8 / 8$ \\
\hline & Mod+V & $2 / 2$ & $3 / 3$ & I & $1 / 1$ & $9 / 9$ & $1 / 1$ \\
\hline \multirow[t]{4}{*}{2} & Is3SG & $8 / 8$ & + & + & + & + & + \\
\hline & V & + & + & + & + & + & + \\
\hline & N & + & + & + & + & + & + \\
\hline & SVO & $25 / 25$ & + & + & + & + & + \\
\hline
\end{tabular}

Table 30.7 An emergence analysis of Samia's syntactic development

Having filled a morphological gap in sample 3, i.e. Aux+ing e.g. where people are sitting, sample 4 witnessed an expansion in Samia's systematic learning into interphasal 
morphology and interclausal syntax, as well as the filling of a gap. At the interphasal stage, 3SG-s became systematic. Another arrival was the lexical morpheme Past-ed e.g. the waiter called the police (220). Syntactically, the subordinate clause stage became evident in two structures. One was Cancel Inversion with the copula e.g. and ab then a girl or boy I don't know what he it is (70). The other was the newly hypothesised 'that' as a Complementiser e.g. the waiter told him that he knows this man (226). Samia continued to use these and previously emerged structures (when contexts permitted) in subsequent samples.

In sum, this emergence analysis shows that Samia commenced the study at the phrasal stage and progressed into the syntax and some of the morphology of stage 4. Although 3SG-s seemed to emerge, there was negative evidence of this morpheme in sample 3. In the following sample, however, it emerged, as did interclausal syntax. Samia's results illustrate how, by tracking continued use of a form in contexts, an EA can detect less analytical approaches, such as 'piggy-backing' on syntax.

\section{CONCLUSIONS AND PEDAGOGICAL IMPLICATIONS}

In applying four learner language methods to the speech of two secondary ESL students, this study illustrates a shift towards the learner's 'eye view'. Via a detailed EA, I have highlighted how analysis can even 'enter' the learner's processing at the point of onset. Thus, criticisms that interlanguage has a deficit emphasis on transition to the target language (e.g. Firth and Wagner, 1997, 2007) have an out-dated notion of the goal of SLA research.

The first research question related to EA's methodological rigor. Rigor is apparent in the tiered analysis of distributional features, systematic productivity and implicational ordering. A particular strength is the separation of formulae from productive tokens. Nevertheless, as the discussion of Samia's 3SG-s emergence exemplified, problem cases do arise. To demonstrate rigour in both difficult and straightforward cases, research should move towards common criteria. Given that both the FA and EA of Amir's 3SGs concurred on the point of acquisition, investigation of the relationship between these two methods would also seem fruitful.

In addressing Lightbown's (1998) criticism of the pedagogical limitations of the ESL stages, the other research question explored an extended set of hypotheses. By lending overall support to twenty-six structures, the results provide a more comprehensive picture of ESL development. They add to growing evidence of the existing hypotheses for morphology (Yamaguchi, 2009; Zhang, this volume) and syntax (Dyson, 2009a). Additionally, 
they provide support for the extended analysis, including elements already attested in Dyson (2009a). However, Amir and Samia's data provide no direct evidence of stage 2 and 3 and their patterns of emergence at the higher stages require further research validation.

Some readers may, nevertheless, wonder how these results would mesh with the ESL classroom. For them, Firth and Wagner's (1997, p. 292ff) argument that interlanguage 'arguably doesn't exist', since learner language is a product of 'recipient design', may ring true. They may conclude that Amir and Samia's social interaction is influencing their speech (cf Mondada and Pekarek-Doehler, 2004). Interestingly, while the tasks undoubtedly shaped Amir and Samia's responses, this pair negotiated the same activities with similar sequences, yet differently.

As grammar teaching comes back on the agenda, learner language analysis warns against the behaviourist assumption that the student is a 'tabula rasa'. Amir and Samia's developmental trajectories complement evidence that teaching works better when students' 'developmental readiness' is considered. Teachers can follow their students' progress, assessing whether a particular form is used and, if so, whether it varies or not (Dyson, 2008; Dyson, 2009b). Such information can inform the selection of what is 'teachable' (Pienemann, 1989), and hence what to 'focus' on next in meaningful, communicative settings (Di Biase, 2008). This learner-oriented approach can be accomplished without ignoring accuracy or explicit instruction (Mansouri and Duffy, 2005).

There is, however, currently no way to connect PT and EA to the social context of the classroom. Currently, PT aims to demonstrate, via the Steadiness Hypothesis ('tasks don't affect stages'), that processability overrides situational context (Pienemann, 1998, pp. 272ff). Problematically, this hypothesis contrasts with counter-claims that context overrides development (Tarone and Liu, 1998).

To show the relationship between context and development, future research could revisit PT's original analysis of social factors (Meisel, Clahsen and Pienemann, 1981). Adopting a different methodology to avoid the previous problems (Hudson, 1993), this research could encompass classrooms factors, such as social interaction (cf Zhang, this volume). As Lafford (2007, p. 746) points out, the investigation of the social context does not mean dispensing with research into 'the psycholinguistic processes that occur within the mind of individual speakers'. Rather, as this paper suggests, it permits a sustainable pedagogy that explores the links between the two. 


\section{ACKNOWLEDGEMENTS}

I would like to express my appreciation to Jane Simpson, for her input into the extended analysis of ESL morphology and syntax, and to the anonymous reviewers for their suggestions and comments. I take full responsibility for the errors that remain.

\section{ENDNOTES}

Previous Processability Theory accounts of ESL (e.g. Pienemann, 2005b; Dyson, 2009a) hypothesized six developmental stages for syntax and five for morphology. To accommodate the reconceptualisation of the syntax (Pienemann, Di Biase and Kawaguchi, 2005) and morphology (see Zhang, this volume), this paper adopts a five-stage model for syntax and a four-stage model for morphology. As a result, based on the two accounts of ESL stage 4 in Pienemann (1998, pp. 174-175) and Pienemann (2005b, p.27), the structures previously included in the additional ESL stage (4), excluding Tense Agreement, have been placed at the sentence level. Since PT (2005) hypothesises a general phrasal exchange at stage 3, VP structures are proposed at this point.

\section{REFERENCES}

Bley-Vroman, Robert (1983). The comparative fallacy in interlanguage studies: The case of systematicity. Language Learning, 33, 1-17.

Bresnan, Joan. (2001). Lexical-functional syntax. Malden, Mass.: Blackwell.

Corder, S (1967). The significance of learners' errors. International Review of Applied Linguistics, $5,161-169$.

Di Biase, Bruno. (2008). Focus-on-form and development in L2 learning. In J.-U. Kessler, (Ed.), Processability approaches to second language acquisition (pp. 197-220). Newcastle, UK: Cambridge Scholars.

Dulay, Heidi; Burt, Marina (1973). Should we teach children syntax? Language Learning, 23, 245-258.

Dyson, Bronwen. (2004). Developmental style in second language processing: A study of inter-learner variation in the acquisition of English as a Second Language. Doctoral dissertation, University of Western Sydney, Australia.

Dyson, Bronwen. (2008). What we learn from questions: ESL question development and its implications for language assessment, Prospect, 23(1), 16-27.

Dyson, Bronwen. (2009a). Processability Theory and the role of morphology in ESL development: A longitudinal study. Second Language Research, 25(3), 355-376.

Dyson, Bronwen. (2009b). Understanding trajectories of academic literacy: How could this improve diagnostic assessment. Journal of Academic Language and Learning, 3(1), 52-69.

Ellis, Rod; Barkuizen, Gary. (2005). Analysing learner language. Oxford: Oxford University Press. 
Falk, Yehuda(2008). Functional relations in the English auxiliary system. Linguistics, 46(5), 861-889. Firth, A; Wagner, J (1997). On discourse, communication, and (some) fundamental concepts in SLA research. The Modern Language Journal, 81, 285-300.

Firth, Alan; Wagner, Johannes. (2007). Second/foreign language learning as a social accomplishment: elaborations on a reconceptualized SLA. The Modern Language Journal, 91, 800-819.

Hudson, Thom. (1993). Nothing does not equal zero: Problems with applying development sequence findings to assessment and pedagogy. Studies in Second Language Acquisition, 15, 461-494.

Kawaguchi, Satomi. (2005). Argument structure and syntactic developments in Japanese as a second language. In M. Pienemann, (Ed.), Cross-linguistic aspects of Processability Theory (pp. 254-298). Amsterdam: John Benjamins Publishing Company.

Klein, Wolfgang; Purdue, Clive. (1992). Utterance structure: developing grammars again. Amsterdam: John Benjamins.

Lafford, Barbara. (2007). Second Language Acquisition reconceptualized?:The impact of Firth and Wagner (1997. Modern Language Journal, 91, 735-756.

Lightbown, Patsy. (1998). The importance of timing in focus on form. In C. Doughty and J. Williams (Eds.), Focus on form in classroom second language acquisition, (pp. 177-196). Cambridge: Cambridge University Press.

Mansouri, Fethi. (2005). Agreement morphology in Arabic as a second language: Typological features and their processing implications. In M. Pienemann. (Ed.), Cross-linguistic aspects of Processability Theory (pp. 117-153). Amsterdam: John Benjamins Publishing Company.

Mansouri, Fethi; Duffy, Loretta (2005). The pedagogic effectiveness of developmental readiness in ESL grammar instruction. Australian Review of Applied Linguistics, 28(1), 81-99.

Meisel, Jurgen; Clahsen, Harald; Pienemann, Manfred (1981). On determining developmental stages in natural second language acquisition. Studies in Second Language Acquisition, 3, 109-135.

Mondada, Lorenza; Pekarek-Doehler, Simona (2004). Second Language Acquisition as situated practice: task accomplishment in the French second language classroom. The Modern Language Journal, 88(4), 501-518.

Parodi, Teresa(2000). Finiteness and verb placement in second language acquisition. Second Language Research, 16(4), 255-381.

Pallotti, Gabrielle. (2007). An operational definition of the emergence criterion. Applied Linguistics, 28(3), 361-382.

Pienemann, Manfred(1984). Psychological constraints on the teachability of languages. Studies in Second Language Acquisition, 6 (2), 186-214.

Pienemann, Manfred. (1989). Is language teachable? Psycholinguistic experiments and hypotheses. Applied Linguistics, 1, 52-79.

Pienemann, Manfred. (1998). Language processing and second language development: Processability theory. Amsterdam: John Benjamins Publishing Company.

Pienemann, Manfred (Ed.). (2005a). Cross-linguistic aspects of Processability Theory. Amsterdam: John Benjamins Publishing Company. 
Pienemann, Manfred. (2005b). An introduction to Processability Theory. In Pienemann, Manfred. (Ed.). Cross-linguistic aspects of Processability Theory (pp. 1-60). Amsterdam: John Benjamins Publishing Company.

Pienemann, Manfred; Di Biase, Bruno; Kawaguchi, Satomi. (2005). Extending Processability Theory. In M. Pienemann. (Ed.), Cross-linguistic aspects of Processability Theory (pp. 199-252). Amsterdam: John Benjamins Publishing Company.

Pienemann, Manfred; Johnston, Malcolm; Brindley, Geoff (1988). Constructing an acquisition-based procedure for second language assessment. Studies in Second Language Acquisition, 10, 217-224.

Tarone, Elaine; Liu, Guo-Qiang. (1995) Situational context, variation, and second language acquisition theory. In G. Cook and B. Seidlhofer, (Eds.), Principle and practice in applied linguistics: Studies in honour of H.G. Widdowson (pp. 107-124). Oxford: Oxford University Press.

Yamaguchi, Yumiko. (2009). The development of plural marking and Phrasal plural in child English L2 acquisition. In J. Kessler and D. Keatinge, (Eds.). Research in second language acquisition: Empirical evidence across languages (pp. 9-40). Newcastle upon Tyne: Cambridge Scholars Publishing.

Zhang, Yanyin(2004). Processing constraints, categorial analysis, and the second language acquisition of the Chinese adjective suffix -de (ADJ. Language Learning, 54, 437-468.

Cite this article as: Dyson, Bronwen. (2010). 'Learner language analytic methods and pedagogical implications'. Australian Review of Applied Linguistics 33 (3), 30.1-30.21. DOI: 10.2104/aral1030. 